\title{
Islet inflammation in type 2 diabetes
}

\author{
Piero Marchetti ${ }^{1}$
}

Received: 20 December 2015 / Accepted: 30 December 2015 /Published online: 19 February 2016

(C) Springer-Verlag Berlin Heidelberg 2016

Keywords Beta cells · Chemokines · Cytokines ·

Inflammation $\cdot$ Macrophages $\cdot$ Type 2 diabetes

\section{Abbreviation \\ CCL Chemokine (C-C motif) ligand}

\section{Introduction}

The term inflammation originates from the Latin, inflammatio, meaning 'setting on fire', and in medicine it indicates the reaction of tissues to injuries induced by different causes. Classically, inflammation is a protective response, which involves many complex signals and aims to repair tissue and restore homeostasis [1]. However, dysregulated or prolonged inflammation states have been associated with many diseases, including type 2 diabetes [1]. Early connections between inflammation, obesity and type 2 diabetes were made in the 1990s, in both rodent models and humans [2, 3], and later substantiated by a large body of evidence (see [4-7] for recent reviews). Then, it was observed that pancreatic islet cells may also show signs of inflammation, including immune cell infiltration [8-10] and increased expression of cytokines and chemokines [11-13]. It has been shown that a proinflammatory milieu can lead to reduced beta cell function and survival [14-16]. Given the key role of beta cell impairment in the

Piero Marchetti

piero.marchetti@med.unipi.it

1 Department of Clinical and Experimental Medicine, Cisanello University Hospital, University of Pisa, Via Paradisa 2, 56124 Pisa, Italy onset and progression of diabetes [17, 18], it is of utmost importance to shed light on the several features linking inflammation and islet cell dysfunction. This commentary on the 'Islet inflammation in type 2 diabetes' symposium at the EASD 2015 meeting focuses on a few general issues regarding the association between inflammation and the pancreatic islets in human type 2 diabetes. It is accompanied by articles that specifically address the mechanistic implications $[19,20]$ and therapeutic perspectives [21].

\section{Immune cell infiltration of pancreatic islets in type 2 diabetes}

Although the majority of work on islet immune cell infiltration has been performed in animal models [5-7, 22, 23], a few studies have been accomplished with human pancreatic tissue from individuals with type 2 diabetes (see Text box). Ehses et al [8] studied the presence and distribution of macrophages (CD68 ${ }^{+}$cells) in the islets of nine type 2 diabetic and seven control individuals. Pancreatic samples were obtained from one diabetic organ donor, eight necropsies (four diabetic and four non-diabetic) and seven surgical resections (four diabetic and three non-diabetic). An average of $35 \pm 12$ islets from diabetic sections and $43 \pm 17$ islets from non-diabetic pancreatic sections were scored to evaluate $\mathrm{CD} 68^{+}$cells at the periphery and/or within the islets. The authors found that the proportion of infiltrated islets (more than three $\mathrm{CD} 68^{+}$cells) in diabetic sections was approximately $16 \%$, with a fourfold increase in comparison with non-diabetic samples. The average number of $\mathrm{CD} 68^{+}$cells per islet was also significantly higher in type 2 diabetic specimens (approximately 1.7 vs 0.7 , with increased intra-islet invasion. Subsequently, Richardson et al studied pancreatic tissue samples obtained at autopsy from 15 type 2 diabetic and 16 non-diabetic individuals 


\begin{tabular}{|c|c|c|c|}
\hline Author (year) & Main findings (macrophages) & Notes & Reference \\
\hline Ehses et al (2007) & Increased infiltration and invasiveness & No difference in granulocytes & [8] \\
\hline Richardson et al (2009) & Increased infiltration & - & [9] \\
\hline Rodriguez-Calvo et al (2014) & Increased CD $45^{+}$leucocytes & Study with isolated islets & [22] \\
\hline Kamata et al (2014) & Increased infiltration & Focus on amyloid-containing islets & [21] \\
\hline Martino et al (2015) & Increased infiltration and invasiveness & $\begin{array}{l}\text { Macrophage infiltration also in the } \\
\text { non-endocrine pancreas }\end{array}$ & [10] \\
\hline
\end{tabular}

[9]. The analysis of 545 diabetic and 564 control islets revealed a significantly higher percentage of islets with more than three $\mathrm{CD}^{+} 8^{+}$cells per islet in diabetic vs control cases $(20.6 \pm 4.1 \%$ vs $4.6 \pm 1.4 \%)$, and demonstrated that the number of $\mathrm{CD}^{+} 8^{+}$cells found in diabetic islets was more than twofold higher compared with that in non-diabetic islets $(1.34 \pm 0.18$ vs $0.52 \pm 0.08$ cells per islet). Additional information comes from a study performed with autopsy samples from Japanese individuals with type 2 diabetes [24]. The authors identified cases with $(n=20)$ or without $(n=20)$ islet amyloid deposition, and demonstrated a significantly greater (approximately threefold) $\mathrm{CD}^{+} 8^{+}$cell infiltration in amyloidladen islets, which correlated with the severity of amyloid deposition. In a later study, Martino et al evaluated pancreatic tissue samples from organ donors (seven without diabetes, six with type 1 diabetes and seven with type 2 diabetes) by using different microscopy techniques (including electron microscopy) to identify islet-infiltrating cells [10]. The authors confirmed a greater islet infiltration by macrophages in the type 2 diabetic sections. In addition, they observed that the pancreatic non-endocrine tissue showed signs of infiltration in the diabetic samples, with the resulting number of macrophages $\left(\mathrm{cell} / \mathrm{mm}^{2}\right.$ pancreatic tissue) significantly higher than in control cases $(18.1 \pm 3.0$ vs $5.2 \pm 1.8)$. This latter observation suggests that in patients with type 2 diabetes the whole pancreatic gland (i.e. its endocrine as well as non-endocrine components) could be inflamed. A similar concept has also emerged in the type 1 diabetes pancreas scenario [10, 25].

Whether other immune cells besides macrophages may also contribute to islet cell infiltration in type 2 diabetes is less clear. Islet lymphocytes have been reported to be (by electron microscopy analysis) or not to be (by immunostaining with anti-CD3 antibodies) increased in pancreatic sections from type 2 diabetic individuals $[8,10]$, with no differences in pancreatic islet granulocytes between diabetic vs non-diabetic samples [8]. Finally, when the immune cells of islets isolated from nondiabetic and type 2 diabetic organ donors were analysed by FACS [26], it was found that CD45 $5^{+}$leucocytes and B (but not T) lymphocytes were higher in the diabetic islets.
In conclusion, evidence obtained by the use of different models (autopsy samples, organ donors, isolated islets) indicates that pancreatic islets in type 2 diabetes show signs of immune cell infiltration, predominantly by macrophages. However, there is still a lack of consensus on the definition of 'insulitis' in type 2 diabetes and the criteria for its diagnosis, and so there needs to be a concerted effort to resolve this, employing a similar approach to that used to establish the definition of insulitis for type 1 diabetes [27].

\section{Heterogeneity and functional role of islet macrophages in type 2 diabetes}

The true significance of islet macrophage infiltration is still incompletely understood. These innate immune system cells are quite heterogeneous, possess functional plasticity and may exert contradictory actions [7, 23]. An attempt has been made to describe these differences by classifying macrophages as being 'classically' activated (M1 macrophages) or 'alternatively' activated (M2 macrophages). Although these two classes are likely to represent the polar ends of a much broader activation spectrum, it is nevertheless assumed that M1 macrophages produce proinflammatory cytokines and are cytotoxic, whereas M2 macrophages contribute to resolving inflammation and promoting tissue repair through several mechanisms, including phagocytosis of apoptotic cells and remodelling the extracellular matrix [7, 23]. In addition, macrophages have been described in the human pancreas at 6-12 weeks of development, suggesting a contribution to pancreas development in humans [28], as more clearly shown in rodents [7].

The relative proportions of M1 and M2 macrophages in the type 2 diabetes infiltrated islets remain undetermined. By using antibodies against CD68 (a likely marker of M1 macrophages) and CD163 (a likely marker of M2 macrophages), one study reported that intraislet-infiltrating macrophages were both $\mathrm{CD} 68^{+}$and $\mathrm{CD} 163^{+}$[8]; however, in a different article it was shown that whereas the number of islet-associated $\mathrm{CD}^{+} 8^{+}$macrophages in type 2 diabetic 
amyloid-positive islets was increased, that of $\mathrm{CD} 163^{+}$cells was not [24].

There have also been conflicting results regarding the possible deleterious actions of islet-infiltrating macrophages. In fact, it has been reported that islets with invading macrophages are characterised by decreased insulin immunoreactivity, increased amyloid deposits, beta cells with oxidative stress-related DNA damage and reduced expression of the gene encoding proinsulin $[8,24]$. However, type 2 diabetic islets with increased $\mathrm{CD} 8^{+}$cells did not display an increased number of $\mathrm{TUNEL}^{+}$cells, and macrophages were not observed in the vicinity of apoptotic beta cells [8]. As for the role of other cells taking part in islet inflammation, the number of $\mathrm{CD} 45^{+}$leucocytes was higher within type 2 diabetic islets with preserved insulin secretion (as assessed by perifusion experiments) as compared with dysfunctional diabetic islets [26].

In conclusion, whereas current information supports the concept that macrophage infiltration may be a main cause of beta cell damage in human type 2 diabetes, a more balanced view (based on macrophage phenotypic heterogeneity) should also take into account the potential beneficial actions of macrophage subpopulations.

\section{Islet expression of cytokines and chemokines in type 2 diabetes}

The expression of cytokines and chemokines at the gene and protein levels has been studied by a few groups to evaluate the presence of molecular signatures of islet inflammation in type 2 diabetic individuals. The most common, comprehensive approach has been the study of the transcriptome of isolated islets. In an early study, the gene profiles of islets isolated from five type 2 diabetic and seven non-diabetic donors were evaluated, with no difference reported between the two groups regarding the expression of the major cytokines and chemokines [29]. A later report described microarray results obtained with islets prepared from six type 2 diabetic and seven non-diabetic organ donors. These revealed the upregulation of the expression a few cytokines (IL-19, IL-25, CSF 1, $L T A$ and IFNB1) and chemokines (CCL5, CCL7, CCL13, CCL16, CCL21, CCL25 and CX3CL1) known to be involved in inflammatory and/or immunomodulatory mechanisms in the diabetic samples [30]. More recently, microarray data were generated by Taneera et al [31] using islets from nine type 2 diabetic individuals and 54 non-diabetic controls. These showed that two proinflammatory chemokines, CCL22 and CXCL5, were downregulated in the diabetic samples. A subsequent study by the same group comparing the islet expression profiles of ten type 2 diabetic and 38 non-diabetic individuals [32], found that the proinflammatory cytokine $I L-6$ and the immunomodulatory cytokines $I L-11$ and $I L-33$ were upregulated in the diabetic cells.

When gene expression was more precisely assessed in a few studies by the use of quantitative RT-PCR, it was found that $I L-1 \beta$ and $C C L 2$ were similarly expressed in islets isolated from seven type 2 diabetic and eight control individuals [33]; however, the authors of a different study observed that $T N F \alpha$ and CCL2 expression levels were higher in type 2 diabetic islets and were associated with reduced glucosestimulated insulin secretion [26].

There are several possible explanations for the discrepancies between these studies. The procedure of islet preparation, based on enzymatic digestion and density gradient purification, can per se induce the expression of inflammatory mediators [34]. In addition, the length of the culture period from isolation to molecular assessments may play a role [35], and, finally, the endocrine cell heterogeneity of the islets precludes the clear determination of the properties of the beta cells [36]. A possible solution to some of these problems is the use of beta cells from frozen pancreas samples, as obtained by laser capture microdissection [37, 38]. Marselli et al [38] published a study comparing the transcriptomics of laser microdissected beta cells prepared from the pancreas of ten type 2 diabetic and ten non-diabetic organ donors. The expression of genes encoding inflammatory and/or immunomodulatory mediators, and that of markers of inflammatory cells were evaluated. $I L-1 \beta$ and $I L-8$ expression trended to be upregulated in the diabetic samples, which was confirmed in a subgroup of cases by quantitative RT-PCR, with clear interindividual differences identified. Furthermore, $I L-11$ was upregulated and $I L-1 \alpha$ was downregulated in the diabetic beta cells; the chemokines upregulated to the greatest extent were CCL2, CCL11 and CCL13.

Evaluation of the presence of $I L-1 \beta$ expression in beta cells by in situ hybridisation [39] showed that this cytokine is present in beta cells from type 2 diabetic individuals but not in those from non-diabetic controls or in the non-endocrine pancreas. There is also some information on the expression of inflammatory mediators in human islet cells at the protein level. When IL-1 $\beta$ was studied in pancreatic samples from five patients with poorly controlled type 2 diabetes [13], double immunostaining for this cytokine and insulin showed the presence of IL-1 $\beta$ in clusters of insulin-containing cells in approximately $20 \%$ of the studied islets. In another study, chemokine (C-C motif) ligand 2 (CCL2) staining colocalised with insulin in both type 2 (two cases studied) and nondiabetic (three cases) sections, with minimal or no CCL2 in glucagon-positive cells [12]. However, quantitative assessments were not performed.

Overall, these results indicate that some cytokines and chemokines are expressed at higher levels in the islets and beta cells of type 2 diabetic individuals, at least in some subgroups of islets and individuals. Islet cells themselves can produce 
some of these molecules when exposed to high concentrations of glucose [13] or the fatty acid palmitate [12, 15], conditions used to mimic a diabetic micro-environment. However, macrophages are likely to be the dominant producers of some toxic cytokines, such as IL-1 $\beta[7,40]$. Whatever the source, the effects of cytokines on beta cell function and survival depend on several other factors, including, in particular, their concentrations and combinations. For example, low levels of IL-1 $\beta$ promote beta cell proliferation and improve insulin secretion $[41,42]$; furthermore, when human beta cell preparations were cultured for 48 or $72 \mathrm{~h}$ with or without IL-1 $\beta, \mathrm{TNF} \alpha$ or IFN $\gamma$, none of these single cytokines was toxic to the beta cells [43].

\section{Conclusions}

Pancreatic islet cell inflammation in type 2 diabetes has been described by several investigators and accepted as a contributory factor to the onset and progression of beta cell failure, at least in subgroups of individuals with this disease. This concept is substantiated by the presence of immune cell infiltration and the altered expression of several cytokines and chemokines in islets of type 2 diabetic individuals. However, islet inflammation might also have beneficial actions on beta cells, depending on the type, amount and combination of the infiltrating cells and expressed cytokines. A better understanding of the mechanisms regulating the several and contradictory effects of inflammation on pancreatic islets will hopefully allow the design and development of effective, safe and targeted therapies for the protection of beta cells in type 2 diabetes.

Funding Work by the author is supported by the Innovative Medicines Initiative Joint Undertaking under grant agreement no. 155005 (IMIDIA), the resources of which are composed of financial contributions from the European Union's Seventh Framework Program (FP7/2007-2013) and the contributions from EFPIA companies.

Duality of interest The author declares that there is no duality of interest associated with this manuscript.

Contribution statement The author was the sole contributor to this paper.

\section{References}

1. Kotas ME, Medzhitov R (2015) Homeostasis, inflammation, and disease susceptibility. Cell 160:816-827

2. Hotamisligil GS, Shargill NS, Spiegelman BM (1993) Adipose expression of tumor necrosis factor- $\alpha$ : direct role in obesitylinked insulin resistance. Science 259:87-91

3. Pickup JC, Crook MA (1998) Is type II diabetes mellitus a disease of the innate immune system? Diabetologia 41:1241-1248
4. Lackey DE, Olefsky JM (2016) Regulation of metabolism by the innate immune system. Nat Rev Endocrinol 12:15-28

5. Hameed I, Masoodi SR, Mir SA, Nabi M, Ghazanfar K, Ganai BA (2015) Type 2 diabetes mellitus: from a metabolic disorder to an inflammatory condition. World J Diabetes 6:598-612

6. Esser N, Legrand-Poels S, Piette J, Scheen AJ, Paquot N (2014) Inflammation as a link between obesity, metabolic syndrome and type 2 diabetes. Diabetes Res Clin Pract 105:141-150

7. Morris DL (2015) Minireview: emerging concepts in islet macrophage biology in type 2 diabetes. Mol Endocrinol 29:946-962

8. Ehses JA, Perren A, Eppler E et al (2007) Increased number of isletassociated macrophages in type 2 diabetes. Diabetes 56:2356-2370

9. Richardson SJ, Willcox A, Bone AJ, Foulis AK, Morgan NG (2009) Islet-associated macrophages in type 2 diabetes. Diabetologia 52:1686-1688

10. Martino L, Masini M, Bugliani M et al (2015) Mast cells infiltrate pancreatic islets in human type 1 diabetes. Diabetologia 58:2554 2562

11. Donath MY, Böni-Schnetzler M, Ellingsgaard H, Halban PA, Ehses JA (2010) Cytokine production by islets in health and diabetes: cellular origin, regulation and function. Trends Endocrinol Metab 21:261-267

12. Igoillo-Esteve M, Marselli L, Cunha DA et al (2010) Palmitate induces a pro-inflammatory response in human pancreatic islets that mimics CCL2 expression by beta cells in type 2 diabetes. Diabetologia 53:1395-1405

13. Maedler K, Sergeev P, Ris F et al (2002) Glucose-induced beta cell production of IL- $1 \beta$ contributes to glucotoxicity in human pancreatic islets. J Clin Invest 110:851-860

14. Donath MY, Størling J, Maedler K, Mandrup-Poulsen T (2003) Inflammatory mediators and islet beta-cell failure: a link between type 1 and type 2 diabetes. J Mol Med (Berl) 81:455-470

15. Cnop M, Abdulkarim B, Bottu G et al (2014) RNA sequencing identifies dysregulation of the human pancreatic islet transcriptome by the saturated fatty acid palmitate. Diabetes 63:1978-1993

16. Eizirik DL, Miani M, Cardozo AK (2013) Signalling danger: endoplasmic reticulum stress and the unfolded protein response in pancreatic islet inflammation. Diabetologia 56:234-241

17. Halban PA, Polonsky KS, Bowden DW et al (2014) $\beta$-Cell failure in type 2 diabetes: postulated mechanisms and prospects for prevention and treatment. J Clin Endocrinol Metab 99:1983-1992

18. Marchetti P, Lupi R, del Guerra S et al (2009) Goals of treatment for type 2 diabetes: beta-cell preservation for glycemic control. Diabetes Care 32(Suppl 2):S178-S183

19. Imai Y, Dobrian A, Morris M, Taylor-Fishwick, Nadler J (2016) Lipids and immune inflammatory pathways of beta cell destruction. Diabetologia. doi:10.1007/s00125-016-3890-y

20. Baltrusch S (2016) Mitochondrial network regulation and its potential interference with inflammatory signals in pancreatic beta cells. Diabetologia doi:10.1007/s00125-016-3891-x

21. Donath MY (2016) Multiple benefits of targeting inflammation in the treatment of type 2 diabetes. Diabetologia doi:10.1007/s00125016-3873-Z

22. Khodabandehloo H, Gorgani-Firuzjaee S, Panahi G, Meshkani R (2016) Molecular and cellular mechanisms linking inflammation to insulin resistance and $\beta$-cell dysfunction. Transl Res 167:228-256

23. Eguchi K, Manabe I (2013) Macrophages and islet inflammation in type 2 diabetes. Diabetes Obes Metab 15(Suppl 3):152-158

24. Kamata K, Mizukami H, Inaba W et al (2014) Islet amyloid with macrophage migration correlates with augmented $\beta$-cell deficits in type 2 diabetic patients. Amyloid 21:191-201

25. Rodriguez-Calvo T, Ekwall O, Amirian N, Zapardiel-Gonzalo J, von Herrath MG (2014) Increased immune cell infiltration of the exocrine pancreas: a possible contribution to the pathogenesis of type 1 diabetes. Diabetes 63:3880-3890 
26. Butcher MJ, Hallinger D, Garcia E et al (2014) Association of proinflammatory cytokines and islet resident leucocytes with islet dysfunction in type 2 diabetes. Diabetologia 57:491-501

27. Campbell-Thompson ML, Atkinson MA, Butler AE et al (2013) The diagnosis of insulitis in human type 1 diabetes. Diabetologia $56: 2541-2543$

28. Banaei-Bouchareb L, Peuchmaur M, Czernichow P, Polak M (2006) A transient microenvironment loaded mainly with macrophages in the early developing human pancreas. J Endocrinol 188: $467-480$

29. Gunton JE, Kulkarni RN, Yim S et al (2005) Loss of ARNT/HIF1 $\beta$ mediates altered gene expression and pancreatic-islet dysfunction in human type 2 diabetes. Cell 122:337-349

30. Bugliani M, Liechti R, Cheon H et al (2013) Microarray analysis of isolated human islet transcriptome in type 2 diabetes and the role of the ubiquitin proteasome system in pancreatic $\beta$ cell dysfunction. Mol Cell Endocrinol 367:1-10

31. Taneera J, Lang S, Sharma A et al (2012) A systems genetics approach identifies genes and pathways for type 2 diabetes in human islets. Cell Metab 16:122-134

32. Mahdi T, Hanzelmann S, Salehi A et al (2012) Secreted frizzledrelated protein 4 reduces insulin secretion and is overexpressed in type 2 diabetes. Cell Metab 16:625-633

33. Welsh N, Cnop M, Kharroubi I et al (2005) Is there a role for locally produced interleukin-1 in the deleterious effects of high glucose or the type 2 diabetes milieu to human pancreatic islets? Diabetes 54 : 3238-3244

34. Johansson U, Olsson A, Gabrielsson S, Nilsson B, Korsgren O (2003) Inflammatory mediators expressed in human islets of Langerhans: implications for islet transplantation. Biochem Biophys Res Commun 308:474-479

35. Negi S, Jetha A, Aikin R et al (2012) Analysis of $\beta$-cell gene expression reveals inflammatory signaling and evidence of dedifferentiation following human islet isolation and culture. PLoS One 7, e30415

36. Bosco D, Armanet M, Morel P et al (2010) Unique arrangement of alpha- and beta-cells in human islets of Langerhans. Diabetes 59: $1202-1210$

37. Marselli L, Sgroi DC, Bonner-Weir S, Weir GC (2009) Laser capture microdissection of human pancreatic $\beta$-cells and RNA preparation for gene expression profiling. Methods Mol Biol 560:87-98

38. Marselli L, Thorne J, Dahiya S et al (2010) Gene expression profiles of $\beta$-cell enriched tissue obtained by laser capture microdissection from subjects with type 2 diabetes. PLoS One 5, e11499

39. Boni-Schnetzler M, Thorne J, Parnaud G et al (2008) Increased interleukin (IL)-1 $\beta$ messenger ribonucleic acid expression in $\beta$ cells of individuals with type 2 diabetes and regulation of IL-1 $\beta$ in human islets by glucose and autostimulation. J Clin Endocrinol Metab 93:4065-4074

40. Nackiewicz D, Dan M, He W et al (2014) TLR2/6 and TLR4activated macrophages contribute to islet inflammation and impair beta cell insulin gene expression via IL-1 and IL-6. Diabetologia 57:1645-1654

41. Maedler K, Schumann DM, Sauter N et al (2006) Low concentration of interleukin- $1 \beta$ induces FLICE-inhibitory protein-mediated betacell proliferation in human pancreatic islets. Diabetes 55:2713-2722

42. Arous C, Ferreira PG, Dermitzakis ET, Halban PA (2015) Short term exposure of beta cells to low concentrations of interleukin$1 \beta$ improves insulin secretion through focal adhesion and actin remodeling and regulation of gene expression. J Biol Chem 290: 6653-6669

43. Hostens K, Pavlovic D, Zambre Y et al (1999) Exposure of human islets to cytokines can result in disproportionately elevated proinsulin release. J Clin Invest 104:67-72 